\title{
Aphanomyces euteiches Inoculum Potential: A Rolled-Towel Bioassay Suitable for Fine-Textured Soils
}

J. L. Williams-Woodward, Graduate Research Assistant, and F. L. Pfleger, Professor, Department of Plant Pathology, R. R. Allmaras, Soil Scientist, USDA-ARS and Department of Soil, Water and Climate, and V. A. Fritz, Associate Professor, Southern Minnesota Experiment Station and Department of Horticulture, University of Minnesota, St. Paul 55108

\begin{abstract}
Williams-Woodward, J. L., Pfleger, F. L., Allmaras, R. R., and Fritz, V. A. 1998. Aphanomyces euteiches inoculum potential: A rolled-towel bioassay suitable for fine-textured soils. Plant Dis. 82:386-390.

A sensitive measure of soil inoculum potential is needed to evaluate field management of common root rot (Aphanomyces euteiches) in peas (Pisum sativum). A modified rolled-towel (RT) bioassay had been proposed to measure soil inoculum potential in fine-textured soils used for pea production in Minnesota. Homogenized soil was used because organic debris containing the inoculum could not be separated by wet sieving. The poor precision prompted an evaluation of procedures to improve this modified RT bioassay. Seed treatment with a 5\% solution of sodium hypochlorite before pea seed germination and plant isolation procedures during the RT bioassay preparation/incubation reduced seedborne contamination and seedling loss to less than $5 \%$. Tests conducted with pasteurized soil that was artificially infested with oospores showed the region of the pea taproot 1 to $2 \mathrm{~cm}$ below the seed to be more susceptible to infection (33\% compared with $15 \%$ infected seedlings) than the region 1 to $2 \mathrm{~cm}$ above the root tip. A soil volume of $1.0 \mathrm{~cm}^{3}$ increased inoculum potential compared with $0.5 \mathrm{~cm}^{3}$ applied to each seedling but did not influence the random error; the 40-seedling compared with the 20 -seedling RT bioassay reduced random error from 18 to $12 \%$. The modified RT bioassay conducted on soil that was artificially infested after steam treatment or without steam treatment showed superior performance when using 40 seedlings compared with 20 seedlings when evaluated for accuracy and precision. Multiple infection theory demonstrated more multiple infections in the RT bioassay with a $0.5 \mathrm{~cm}^{3}$ soil volume applied to each seedling, which shows that soil mass is a factor preventing a higher percentage of infected seedlings. These modifications to the RT bioassay improved the method enough to reduce the random error by one-half compared with using homogenized soil without the proposed modifications.
\end{abstract}

Common root rot of pea (Pisum sativum L.), caused by Aphanomyces euteiches Drechs., is a serious disease for pea production in Minnesota and the upper Midwest (9). Much of this production is on fine-textured soils, some of which have imperfect to poor natural drainage. Fungicides are generally not effective for controlling root rot, and nearly all cultivars have little tolerance to this disease in heavily infested fields; current control is avoidance of fields with high potential for disease based on a soil indexing procedure $(17,18)$. An oat (Avena sativa L.) precrop with a specific time and method of oat residue incorporation into the soil has shown promise for suppression of $\mathrm{A}$. euteiches root rot, but only when surface

Corresponding author: F. L. Pfleger

E-mail: francisp@puccini.crl.umn.edu

Contribution 21,645 of the Minnesota Agricultural Experiment Station.

Accepted for publication 30 December 1997.

Publication no. D-1998-0209-02R

(C) 1998 The American Phytopathological Society compaction is avoided (7). When rainfall is excessive during germination and early growth of peas, the cultural control of an oat precrop fails because all seedlings become severely diseased. Abiotic stresses under these conditions may have both direct and indirect effects (1).

A dilution plating technique has not been developed to quantify populations of A. euteiches because oospore germination in vitro is not consistent and no selective medium has been developed to isolate the fungus from soil. Although a soil indexing method (17) is commonly used to locate fields with high disease potential, the method lacks the precision and specificity necessary for quantitative studies involving A. euteiches populations and associated inoculum potential. Other plant bioassays estimate inoculum potential using the most probable number method (16) and the rolled-towel (RT) bioassay $(10,13)$. These methods have advantages because of convenience and their potential for use in pathogen population studies related to specific practices for disease control. Although the RT bioassay cannot quantify populations of A. euteiches as in a dilution plating technique, it measures inoculum potential, which indexes inoculum density, inoculum (capacity), and soil factors that may inhibit or promote infection of the roots (11).

Malvick et al. (12) developed an RT bioassay, in which crushed and homogenized air-dried soil was used instead of the organic debris sieved from homogenized soil $(10,13)$. Fine-textured soils from infested fields in Minnesota yielded small and insufficient amounts of organic material on a 200-mesh sieve after a blender was used to homogenize the soil. The RT and most probable number bioassay used to estimate inoculum potential in artificially infested sand, loam, and clay loam soils, and naturally infested clay loams (12) showed a large variability between bioassay methods and between repeats of the RT bioassay using 20 or 40 pea seedlings. In the case of artificially infested soils, they noted that clustering of oospores may have caused significant variability.

Three separate modifications of the RT bioassay were tested to improve precision and reliability for measuring A. euteiches inoculum potential. These modifications were to evaluate sensitivity of the bioassay as related to (i) a region of the pea taproot most susceptible to A. euteiches infection, (ii) the amount of homogenized soil placed onto each seedling, and (iii) the inherent bioassay procedures including seedling number and method of packaging the rolled towel.

\section{MATERIALS AND METHODS}

Soil infestation. A. euteiches (isolate Ae467 obtained from C. Grau, University of Wisconsin, Madison) originally isolated from pea was cultured on corn meal agar (CMA; Difco, Detroit, MI) for 4 to 5 weeks at $23^{\circ} \mathrm{C}$ in the dark. Oospores were then separated from the agar and mycelium by homogenizing the culture in sterile deionized water with a Polytron mixer (Kinematica AG, Littau, Switzerland). The oospore suspension was frozen and stored until used to infest soil.

Topsoil from a Nicollet sandy clay loam (fine-loamy, mixed, mesic aquic Hapludoll; $\mathrm{pH} 7.0,3.5 \%$ organic matter, $51 \%$ sand, $26 \%$ silt, and $23 \%$ clay) was obtained from a field near Waseca, Minnesota, that had no history of common root rot and had never been planted to peas. One lot of soil was steamed twice at $60^{\circ} \mathrm{C}$ for $1 \mathrm{~h}$ after a 
24-h interval; another lot was not steam treated. Test soil was prepared somewhat differently for experiments A and B.

For experiment A, oospores of $\mathrm{A}$. $\mathrm{eu}$ teiches were counted using a hemacytometer and blended into steam-treated soil at concentrations of 100, 500, 1,000, 1,500, and 2,000 oospores per $\mathrm{cm}^{3}$ of soil. Based upon soil volume-to-mass relations, these volumetric concentrations corresponded to $83,417,833,1,250$, and 1,667 oospores per $\mathrm{g}$ of soil. Infested soil was air-dried for $24 \mathrm{~h}$ at $24^{\circ} \mathrm{C}$ to a gravimetric water content of $4 \%$ and then stored until use.

For experiment B, oospores were incorporated into the steam-treated and nonsteam-treated soil at a rate to obtain 83 oospores per $g$ of dry soil. Separate lots of the steam-treated and non-steam-treated soil were not infested.

The RT bioassay. The RT bioassay was prepared and evaluated with some modifications of methods described earlier $(10,12,13)$. Homogenized soil was used in the assays rather than organic debris that had been wet-sieve separated from the soil $(10,13)$.

Pea seed (Perfection 8221; Nunhems Seed Corp., Lewisville, ID) was surface treated with a $5 \%$ solution of sodium hypochlorite for $5 \mathrm{~min}$, rinsed with sterile distilled water, and then placed into moistened sterile vermiculite for 4 to 5 days at $22^{\circ} \mathrm{C}$. Four germinated pea seedlings with root lengths approximately 6 to $8 \mathrm{~cm}$ were placed side-by-side on a moistened paper towel (bleached, $26 \times 34 \mathrm{~cm}$ ). Next, a volume of the test soil $\left(0.5\right.$ or $1.0 \mathrm{~cm}^{3}$ corresponding to 0.6 and $1.2 \mathrm{~g}$, respectively) was placed onto each root, either within 2 $\mathrm{cm}$ of the pea seed or within $2 \mathrm{~cm}$ above the root tip. Seedlings and soil were then covered with another paper towel and moistened; a plastic film was placed over the paper towel, and the towels were gently rolled into a cylinder that contained the four seedlings. This procedure involving the four seedlings was performed 5 or 10 times to assemble a 20 - or 40 -seedling RT bioassay, respectively.

Each RT bioassay (20 or 40 seedlings) was placed inside a plastic bag and watered with $250 \mathrm{ml}$ of pentachloronitrobenzene solution (PCNB; Terraclor, $75 \%$ wettable powder, Olin Corp., Little Rock, AR) at 1.0 $\mathrm{g} /$ liter. These RT bioassay assemblies were incubated in an upright position at $23^{\circ} \mathrm{C}$ with $70 \% \mathrm{RH}$ and a 14-h photoperiod in a growth chamber, and were maintained moist by periodic watering with deionized water.

After 7 days, each RT bioassay was opened to evaluate and remove seedborne contaminated seedlings and to clip secondary roots according to Engelkes and Windels (6). Final evaluations were made after $20 \pm 1$ days. Seedlings with typical symptoms of A. euteiches root rot (honey yellow coloration, loss of turgor, and cortex easily removed from root stele) were counted and recorded as the percent diseased in the 20- or 40-seedling RT bioassay. Periodic culturing of diseased root tissue on semiselective medium $(12,15)$ confirmed the presence of A. euteiches.

Inoculum potential in the RT bioassay (x) was expressed as the percentage of noncontaminated pea seedlings with symptoms typical of $A$. euteiches infection. Before statistical analyses using an analysis of variance (ANOVA), the bioassay datum (x) was transformed: $y=\sin ^{-1}(x / 100)^{0.5}$. When observed $x$ was zero (no infected seedlings), a value of $2.5 \%$ was inserted before transforming. For other analyses, including mean inoculum potential and estimates of error, the data were not transformed.

Region of pea-seedling root most sensitive to A. euteiches infection. The RT bioassay selected for this test consisted of the $0.5 \mathrm{~cm}^{3}$ soil volume, the 20 -seedling assembly, and a steamed soil infested with 83 oospores per $g$ of soil. Two regions of the pea seedling taproot were tested for placement of the test soil: within $2 \mathrm{~cm}$ of the pea seed and within $2 \mathrm{~cm}$ of the root tip. For each placement, the RT bioassay was performed twice.

Evaluation of the RT bioassay: experiment A. The volume of soil placed on the pea seedling $\left(0.5\right.$ or $1.0 \mathrm{~cm}^{3}$ soil), the number of seedlings per bioassay (20 or 40 seedlings), and the number of repetitions of the bioassay were tested at six inoculum levels $(100,500,1,000,1,500$, and 2,000 oospores per $\mathrm{cm}^{3}$ of soil) of artificially infested soil that was previously steam treated. Separate tests were conducted on steam-treated soil that was not artificially infested. The two-factor two-level factorial combination of soil volume and number of seedlings in a bioassay was tested using five replicates in a randomized complete block design.

Inoculum potential, as a percentage of diseased pea seedlings infected with $A$. euteiches in each RT bioassay, was subjected to an analysis to obtain duplication error. For this analysis, two replicates out of five RT bioassays were randomly selected for each of the 100, 500, 1,000, 1,500 , and 2,000 levels of oospore infestation per $\mathrm{cm}^{3}$ of soil, and the duplication error was determined. An additional replicate was drawn at random from the data bank, and another analysis was performed to obtain the duplication error until all five replicates were included in the analyses.

Using all five replicates of the bioassay data, a mathematical fit was made to an equation of the form: $y^{\prime}=\left(1-e^{\alpha x^{\prime}}\right)$, where $y^{\prime}$ is the fraction of diseased seedlings, $x^{\prime}$ is the number of oospores per $\mathrm{cm}^{3}$ of infested soil, and $\alpha$ is a fitting parameter that scales the variable $x^{\prime}$ according to the estimated value of $y^{\prime}$ at 2,000 oospores per $\mathrm{cm}^{3}$ of soil. This mathematical form was used to evaluate multiple infections $(2,3)$.

Application of the RT bioassay: experiment B. The RT bioassay was used to measure inoculum potential in steamed and nonsteamed topsoil after artificial infestation (83 oospores of A. euteiches per $g$ of dry soil) and subsequent use in a greenhouse test of green manuring effects. Details of the materials and methods in this experiment are given by Williams-Woodward et al. (19). Artificially infested soil was placed in cone-shaped plastic containers, and one of nine precrops was grown with frequent watering to duplicate wet soil conditions in the field. After a 5-week growth period, the shoot was clipped and mixed back into the soil of the same container, and allowed to decompose as a green manure during a 4-week period. After the incubation period, the $A$. euteiches-susceptible pea $(P$. sativum cv. Target) was grown and the soil was removed, air-dried, and homogenized for the RT bioassay. Five replicates of the green manure test were conducted, and duplicate RT bioassays were prepared per sample of soil obtained from each cone-shaped container.

Nine precrops were tested for their green manure effect: alfalfa (Medicago sativa $\mathrm{L}$. cv. Nitro), snap bean (Phaseolus vulgaris L. cv. Hystyle), soybean (Glycine max (L.) Merr. cv. Sturdy), sweet corn (Zea mays L. cv. Jubilee), high glucosinolate rape (Brassica napus L. cv. Humus), two cultivars of oat (A. sativa cvs. Troy and Dane), and pea (P. sativum cv. Target). Fallow (or no crop) was also included.

The entire experiment was repeated: a 20 -seedling RT bioassay was used in the first experiment, while a 40-seedling RT bioassay was used in the second. In both sets of RT bioassay, the soil volume applied per seedling was $0.5 \mathrm{~cm}^{3}$.

The RT bioassay was used to measure inoculum potential in the steamed and nonsteamed soil that was not artificially infested. The same green manure test was conducted, except that there was only one replicate, but with duplicate RT bioassay made on the soil in each cone-shaped container.

\section{RESULTS}

Seedborne contamination. Before using the fungicide and related procedures, as many as $90 \%$ (generally 40 to $50 \%$ ) of the seedlings were infected with pathogens other than A. euteiches. However, when the fungicide solution was used, seedling loss (contamination) was never more than 2.5 to $5 \%$ of the original 40 seedlings in the RT bioassay.

Region of the pea taproot infected by A. euteiches. The region of the pea taproot located 1 to $2 \mathrm{~cm}$ below the seed was more susceptible to infection by $A$. euteiches than the region 1 to $2 \mathrm{~cm}$ above the root tip; the means were different statistically $(P<0.01)$. Nearly $33 \%$ of the seedlings were diseased when soil was placed near the seed compared with $15 \%$ when pea seedlings were inoculated 1 to $2 \mathrm{~cm}$ above 
the root tip. The distance between the two inoculated regions was 4 to $6 \mathrm{~cm}$.

RT bioassay variability: experiment A. A three-factor ANOVA performed on diseased seedlings in the RT bioassay indicated significant effects $(P<0.001)$ related to the number of $A$. euteiches oospores in the sandy-clay-loam topsoil, amount of test soil applied, and the interaction of number of oospores and number of seedlings evaluated in each bioassay (Table 1). The mean percentage of diseased seedlings was $11.3,22.6,36.3,58.4$, and $51.7 \%$ when exposed to soil with 100, 500, 1,000, 1,500 , and 2,000 oospores per $\mathrm{cm}^{3}$ of soil, respectively. This array of diseased seedlings suggests multiple infection and perhaps clustering of oospores at their highest concentrations. The number of pea seedlings used in each RT bioassay (20 or 40 seedlings) did not have a statistically significant effect. The mean percentage of greater when $1.0 \mathrm{~cm}^{3}$ of soil $(40.6 \%)$ was used compared with $0.5 \mathrm{~cm}^{3}$ of soil $(27.8 \%)$. Subsequent analyses explain the significant interaction between number of oospores and number of seedlings in the 20- versus 40-seedling RT bioassay as a function of oospore numbers in the test soil.

Estimates of SE (a standard error derived from repeat bioassays on the same soil sample) were not changed as the number of replicates increased, although the degrees of freedom in the SE increased (Table 2). The SE was not sensitive to the diseased seedlings per RT bioassay was

number of oospores per $\mathrm{cm}^{3}$ of soil (not shown). When five replicates were used to estimate SE, the amount of soil used per seedling in the RT bioassay had no effect on random error, but the 20 -seedling RT bioassay had a higher random error than the 40 -seedling RT bioassay (18.5\% compared with $12.3 \%$ diseased seedlings). These SE are close to their expected ratio of 1.4 based on $n^{0.5}$.

All four schemes of soil applied per seedling and number of seedlings in the RT bioassay show evidence for multiple infections (Fig. 1); otherwise the fraction of diseased seedlings would be linearly related to the number of oospores per $\mathrm{cm}^{3}$ of soil (3). These functions had $R^{2}$ ranging from 0.72 to 0.86 , and the $\alpha$ values were distinctly different depending on the amount of soil placed on each seedling in the RT bioassay (Table 3). These extremely small values of $\alpha$ suggest that most of the oospores were inactive or did not produce a diseased seedling if they had germinated. Solution of the equation $\left(y^{\prime}=1-e^{\alpha x^{\prime}}\right)$ for $\alpha x^{\prime}$ yields the quantity $\ln \left[1 /\left(1-y^{\prime}\right)\right]$, which estimated the number of infections.

The fitted equations and the means of five replicates at a given oospore concentration are presented in Figure 1. A reduced sums of squares (of the residual source in the regression) test (14) showed that the treatment effects of soil volume and number of seedlings in an RT bioassay were statistically different $(P<0.001)$. The deviations of means from the fitted equations at the concentration of 100 oospores per

Table 1. Analysis of variance for components of variation. Percentage of diseased pea seedlings observed in rolled-towel bioassays using soil artificially infested with Aphanomyces euteiches oospores

\begin{tabular}{lccc}
\hline Source of variation & df & Mean square & $\boldsymbol{F}$ value $^{\mathbf{a}}$ \\
\hline Oospores $/ \mathrm{cm}^{3}(\mathrm{O})^{\mathrm{b}}$ & 5 & 6,967 & $59.7^{*}$ \\
Amount of soil applied $(\mathrm{W})^{\mathrm{c}}$ & 1 & 3,425 & $29.4^{*}$ \\
Number of seedlings $(\mathrm{S})^{\mathrm{d}}$ & 1 & 30 & 0.3 \\
$\mathrm{O} \times \mathrm{W}$ & 5 & 236 & 2.0 \\
$\mathrm{O} \times \mathrm{S}$ & 5 & 824 & $7.1 *$ \\
$\mathrm{~W} \times \mathrm{S}$ & 1 & 106 & 0.9 \\
$\mathrm{O} \times \mathrm{W} \times \mathrm{S}$ & 5 & 197 & 1.7 \\
Error & 96 & 117 & - \\
\hline
\end{tabular}

a $*=F$ values significant at $P<0.001$.

${ }^{\mathrm{b}}$ Number of A. euteiches oospores used to artificially infest the sandy clay loam topsoil.

${ }^{c}$ Amount of topsoil $\left(0.5\right.$ or $\left.1.0 \mathrm{~cm}^{3}\right)$ applied to each seedling.

${ }^{\mathrm{d}}$ Number of pea seedlings ( 20 or 40 ) evaluated in each bioassay.

Table 2. True random error (SE) obtained from a rolled-towel (RT) bioassay (\% seedlings diseased) performed on a steam-treated sandy clay loam soil artificially infested with Aphanomyces euteiches oospores

\begin{tabular}{|c|c|c|c|c|}
\hline \multirow{3}{*}{$\begin{array}{l}\text { Replicates } \\
\text { in the } S^{a}\end{array}$} & \multicolumn{4}{|c|}{ Diseased seedlings (\%) } \\
\hline & \multicolumn{2}{|c|}{$0.5 \mathrm{~cm}^{3}$ of soil ${ }^{b}$} & \multicolumn{2}{|c|}{$1.0 \mathrm{~cm}^{3}$ of soil } \\
\hline & 20 seedlings $^{c}$ & 40 seedlings & 20 seedlings & 40 seedlings \\
\hline 2 & 18.1 & 6.9 & 22.4 & 11.2 \\
\hline 3 & 13.3 & 17.0 & 13.7 & 11.6 \\
\hline 4 & 15.1 & 14.0 & 16.3 & 12.3 \\
\hline 5 & 18.1 & 13.6 & 18.9 & 11.0 \\
\hline
\end{tabular}

${ }^{a}$ A replicate is one bioassay performed on each of the five levels of oospores added to the test soil.

b Volume of crushed topsoil $\left(0.5\right.$ and $\left.1.0 \mathrm{~cm}^{3}\right)$ applied to each seedling root in an RT bioassay.

${ }^{\mathrm{c}}$ Number of seedlings in a single RT bioassay. $\mathrm{cm}^{3}$ of soil suggest more sensitivity at low concentrations of oospores, and the tendency of the means to drop below the fitted equations at concentrations above 1,500 oospores per $\mathrm{cm}^{3}$ of soil suggests a clustering reaction independent of the multiple infection phenomena.

Application of the RT bioassay: experiment B. Several precrops (pea, alfalfa, snap bean), when followed by a susceptible pea, had an increased measured inoculum potential of $A$. euteiches relative to no precrop (no crop) after artificial infestation of steamed and nonsteamed soil. Several other precrops (oat cv. Troy, rapeseed, sweet corn), when followed by a susceptible pea, had a decreased inoculum potential (Table 4). In 13 out of 18 comparisons, the 40-seedling RT bioassay gave higher measured inoculum potential than the 20seedling RT; a similar observation was made in experiment A (Fig. 1) when there was no soil treatment after artificial infestation and the number of oospores was less than 500 per $\mathrm{cm}^{3}$ of soil. Both observations may relate to the larger amount of PCNB per seedling added to the 20-seedling RT bioassay during incubation. The random error, SE, in the 20-seedling RT bioassay was nearly 1.5 times larger than in the 40 seedling RT bioassay, similar to that observed in experiment A (Table 2). Inoculum potential in the study with the 40seedling RT bioassay was higher in the steamed soil except at lower levels of inoculum potential, when there was no difference. Inoculum potential in the study with the 20-seedling RT was higher in the nonsteamed soil as a mean over all crops. There is no apparent process explanation, but it does appear that the 40-seedling RT bioassay is less susceptible to bias because it measures a higher inoculum potential.

The mean inoculum potential in the nonsteamed and noninfested soil was $4.1 \pm$ $2.2 \%$, as measured by the 40 -seedling RT bioassay. Even though this soil was selected from a field that had no history of common root rot, there was a low but real level of A. euteiches inoculum present. Eighteen RT bioassay measurements on the steamed soil produced only one false positive.

\section{DISCUSSION}

The original RT bioassay for estimating inoculum potential of $A$. euteiches in soil $(10,13)$ used organic debris separated by wet-sieving the soil. Malvick et al. (12) modified the RT bioassay to use homogenized whole soil because they could not recover organic material from fine-textured soils used for pea production in Minnesota. Although the method facilitated the measurement of inoculum potential of A. euteiches, the duplication error was roughly $30 \%$ when assays were made on artificially infested sand and on soils with a loam and sandy clay loam texture. Duplication errors were roughly $25 \%$ when applied to natu- 
rally infested sandy clay loam (12). Random error, when wet-sieve separated organic debris was used in the RT bioassay, was estimated to be less than $7 \%$ (10). Tested improvements over the Malvick et al. (12) procedure were the site for placement of the test soil onto the seedling root, the number of seedlings used in each RT bioassay, use of PCNB during initial wetting of the bioassay, and use of a plastic film wrap to reduce seedling cross-contamination upon rolling the ribbon of four seedlings side-by-side.

These latter two procedures reduced the number of contaminated seedlings to one or two per 40-seedling RT bioassay. At least $50 \%$ of the RT bioassays had no contaminated seedlings.

When soil was placed on the pea taproot 1 to $2 \mathrm{~cm}$ below the seed, the number of diseased seedlings per RT bioassay was $100 \%$ greater than when the soil was placed 1 to $2 \mathrm{~cm}$ above the root tip. This region of the root is more susceptible to $A$. euteiches infection and corresponds to the region of root differentiation where secondary roots emerge and root hairs are prominent in early stages of root development. Exudation in this region of the root is likely to stimulate oospore germination (4). The Mitchell et al. (13) method specified soil placement near the root tip, where taproot elongation is most active, but field and laboratory observations of Burke et al. (4) suggested that the region of the taproot near the pea seed should be more susceptible to A. euteiches infection than the region near the root tip.

After improvements were made in the RT bioassay as related to pea seed contamination and cross-contamination in the rolled-towel assembly, and the most sensitive region of the pea taproot of $\mathrm{A}$. $\mathrm{eu}$ teiches infection was determined, the alternatives of soil volume $\left(0.5\right.$ or $\left.1.0 \mathrm{~cm}^{3}\right)$ and seedling number ( 20 or 40 seedlings) were then tested for random error. Although the measured mean seedling disease was $40.6 \%$ with $1.0 \mathrm{~cm}^{3}$ soil volume, compared with $27.8 \%$ with the $0.5 \mathrm{~cm}^{3}$ soil volume, there was no effect on random error.

The use of 20 versus 40 seedlings in the RT bioassay had no effect on the mean measured inoculum potential in experiment A using artificially infested steamed soil, but the random error with the 40 -seedling RT bioassay was roughly $12.3 \%$ compared with $18.5 \%$ with the 20 -seedling RT bioassay. Respective values of random error when applied to soil (steamed or nonsteamed) exposed to plant rooting after artificial infestation in experiment B were 7.1 and $13.6 \%$. These random errors are close to the $n^{0.5}=1.4$ relation.

Analysis of diseased seedlings as a function of the number of oospores per $\mathrm{cm}^{3}$ of soil infested into steamed soil was corrected for multiple infection. This analysis demonstrated the small fraction of oospores involved in disease. Multiple

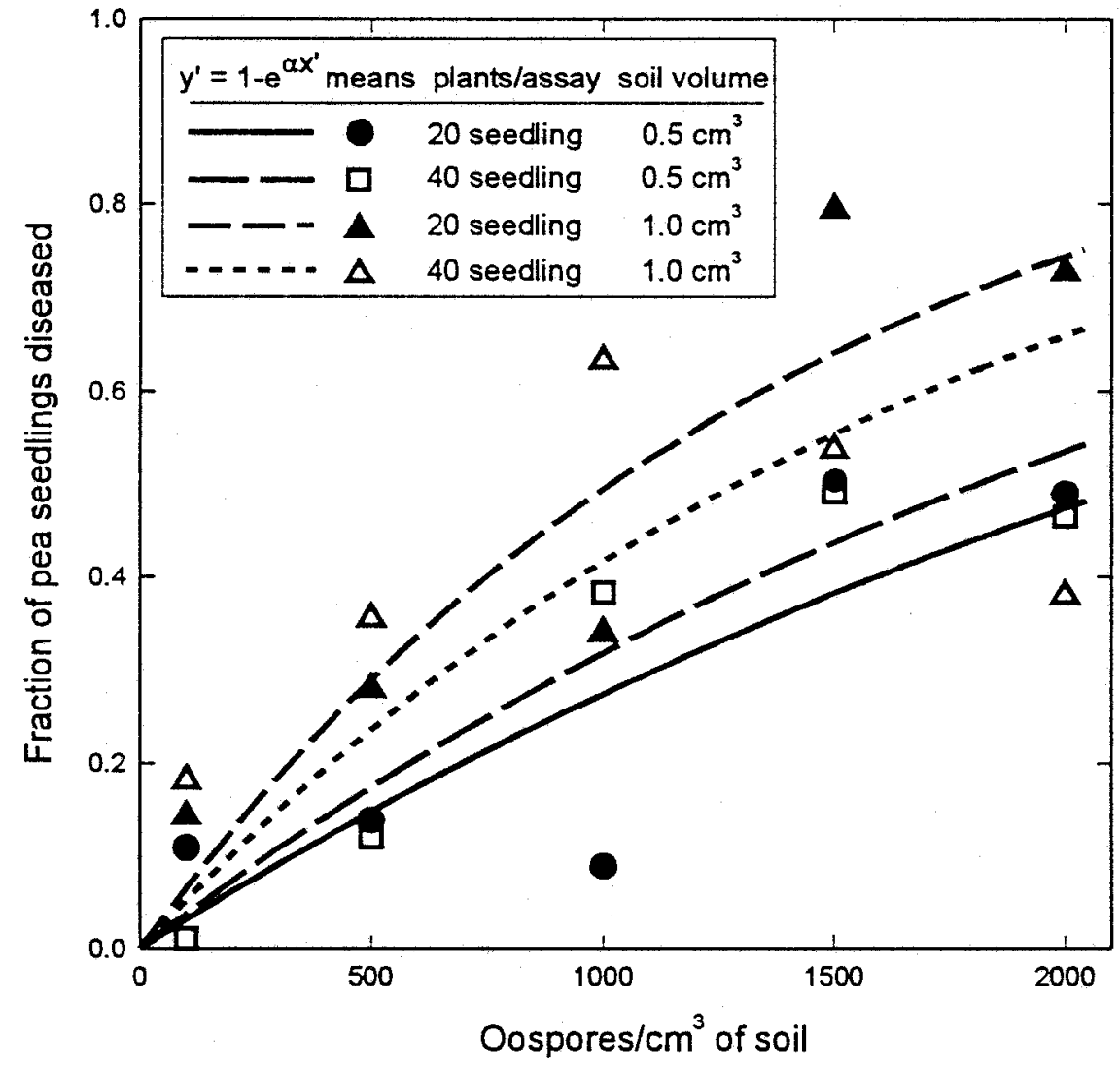

Fig 1. A multiple-infection plot of inoculum potential (fraction of pea seedlings diseased) in the rolled-towel (RT) bioassay as related to the number of oospores used to artificially infest a steamtreated topsoil with a sandy clay loam texture.

Table 3. Parameters associated with the multiple infection relations in Figure 1

\begin{tabular}{ccccc}
\hline \multicolumn{2}{c}{ Rolled-towel bioassay combination } & & \multicolumn{2}{c}{ Parameters in multiple infection function } \\
\cline { 1 - 2 } Volume of soil $\left(\mathbf{c m}^{\mathbf{3}}\right)$ & Seedlings (no.) & & $\boldsymbol{R}^{\mathbf{2}}$ & $\boldsymbol{\alpha}^{\mathbf{b}}$ \\
\hline 0.5 & 20 & 0.72 & 3.213 \\
& 40 & 0.86 & 3.833 \\
1.0 & 20 & 0.86 & 6.828 \\
& 40 & & 0.81 & 5.386 \\
\hline
\end{tabular}

a Multiple infection function: $y^{\prime}=1-e^{\alpha x^{\prime}}$.

b Multiply the parameter values by $10^{-4}$.

Table 4. Inoculum potential (rolled-towel bioassay) in artificially infested soil (steamed or nonsteamed) after growing a susceptible pea cultivar following green manure treatment of soil by nine different precrops

\begin{tabular}{|c|c|c|c|c|}
\hline \multirow[b]{3}{*}{ Precrop } & \multicolumn{4}{|c|}{ Infected seedlings $(\%)^{\mathrm{a}}$} \\
\hline & \multicolumn{2}{|c|}{ 20-seedling bioassay ${ }^{b}$} & \multicolumn{2}{|c|}{ 40-seedling bioassay } \\
\hline & Steamed & Nonsteamed & Steamed & Nonsteamed \\
\hline No crop & 7.1 & 10.8 & 30.3 & 13.6 \\
\hline Pea & 31.5 & 22.9 & 67.0 & 40.2 \\
\hline Alfalfa & 9.3 & 19.6 & 61.9 & 12.0 \\
\hline Oat - Troy & 0.5 & 12.5 & 3.8 & 4.5 \\
\hline Sweet corn & 4.7 & 10.4 & 7.3 & 4.6 \\
\hline Rapeseed & 12.8 & 7.3 & 7.6 & 11.0 \\
\hline Soybean & 8.8 & 20.5 & 10.2 & 12.7 \\
\hline Oat - Dane & 7.3 & 13.7 & 15.5 & 14.3 \\
\hline Snap bean & 6.5 & 14.7 & 36.5 & 11.5 \\
\hline $\mathrm{s}_{\mathrm{x}^{\prime}}$ & 5.1 & 4.8 & & \\
\hline SE & 13.6 & 7.1 & & \\
\hline
\end{tabular}

a Each entry is the mean of 10 determinations (or bioassay); the 20-seedling and 40-seedling bioassay were applied to separate runs of the experiment described by Williams-Woodward et al. (19); $\mathrm{s}_{\mathrm{x}^{\prime}}$ with $72 \mathrm{df}$ was derived from the experimental error; SE with $90 \mathrm{df}$ is the true duplication error obtained by two separate bioassays on the same homogenized bulk soil sample.

${ }^{\mathrm{b}} 0.5 \mathrm{~cm}^{3}$ of soil spotted onto each pea seedling. 
infection rate was higher when using the $0.5 \mathrm{~cm}^{3}$ than when using the $1.0 \mathrm{~cm}^{3}$ soil volume, which suggests that the fraction of diseased seedlings cannot rise much above the $0.5 \mathrm{~cm}^{3}$ treatment due to a mass of soil separating pathogen and host in the RT bioassay. Seedling number in the RT bioassay had no effect, as expected. At the high concentrations of oospores per $\mathrm{cm}^{3}$ of soil, there was a decrease of diseased pea seedlings. Such an antagonistic interaction among oospores may be a result of clustering (8). Chan and Close (5) noted a recovery of oospores and a disease severity from soil artificially infested with $\mathrm{A}$. euteiches that were both curvilinearly related to the number of oospores infested, but they did not explain their results as a multiple infection phenomenon.

Based upon the tests in Table 2 and the functions displayed in Figure 1, the suggested procedure is to use a 40 -seedling RT bioassay with a soil volume of $0.5 \mathrm{~cm}^{3}$ or $1.0 \mathrm{~cm}^{3}$, depending on the expected range of inoculum potential (percentage of seedlings expected to be diseased). The advantage of more than a duplicate RT bioassay is experimental error reduction and an improved mean estimate. This is the procedure adopted for inoculum potential determinations in field studies $(7,19)$.

As the measured inoculum potential increases and approaches $90 \%$ diseased seedlings, accuracy should improve and random error decrease. In a 15-seedling RT bioassay using wet-sieve separated organic debris (10), the measured inoculum potential was nearly $100 \%$ after 3 weeks. Further tests are needed to improve the percentage of diseased seed- lings when organic debris is difficult to separate from the soil.

\section{ACKNOWLEDGMENTS}

We gratefully acknowledge the partial financial support provided by the Greater Minnesota Corporation/Agricultural Utilization and Research Institute and Cool Season Food Legume CSRS Special Grant.

\section{LITERATURE CITED}

1. Allmaras, R. R., Fritz, V. A., Pfleger, F. L., and Copeland, S. M. Common root rot of pea (Pisum sativum L.): Oat precrop and traffic compaction effects on fine-textured mollisols. In: Proc. Sympos. Int. Soc. Root Res., 5th. Clemson University, Plant Soil. In press.

2. Baker, R. 1971. Analyses involving inoculum density of soil-borne plant pathogens in epidemiology. Phytopathology 61:1280-1292.

3. Baker, R., and Drury, R. 1981. Inoculum potential and soilborne pathogens: The essence of every model is within the frame. Phytopathology 71:363-372.

4. Burke, D. W., Hagedorn, D. J., and Mitchell, J. E. 1969. Aphanomyces and Fusarium root rot of peas with partial vs. total exposure of roots to infested soil. Phytopathology 59:1261-1266.

5. Chan, M. K. Y., and Close, R. C. 1987. Aphanomyces root rot of peas. 1. Evaluation of methods for assessing inoculum density of Aphanomyces euteiches in soil. N.Z. J. Agric. Res. 30:213-217.

6. Engelkes, C. A., and Windels, C. E. 1994. $\beta$ escin (saponin), oat seedlings, and oat residue in soil affects growth of Aphanomyces cochlioides hyphae, zoospores, and oogonia. (Abstr.) Phytopathology 84:1158.

7. Fritz, V. A., Allmaras, R. R., Pfleger, F. L., and Davis, D. W. 1995. Oat residue and soil compaction influences on common root rot (Aphanomyces euteiches) of peas in a finetextured soil. Plant Soil 171:235-244.

8. Gilligan, C. A. 1985. Probability models for host infection by soilborne fungi. Phytopa- thology 75:61-67.

9. Hagedorn, D. J., ed. 1984. Compendium of Pea Diseases. American Phytopathological Society. St. Paul, MN.

10. Kraft, J. M., Marcinkowska, J., and Muehlbauer, F. J. 1990. Detection of Aphanomyces euteiches in field soil from northern Idaho by a wet-sieving/baiting technique. Plant Dis. 74:716-718.

11. Lockwood, J. L. 1986. Soilborne plant pathogens: Concepts and connections. Phytopathology 76:20-27.

12. Malvick, D. K., Percich, J. A., Pfleger, F. L., Givens, J., and Williams, J. L. 1994. Evaluation of methods for estimating inoculum potential of Aphanomyces euteiches in soil. Plant Dis. 78:361-365.

13. Mitchell, J. E., Bhalla, H. S., and Yang, G. H. 1969. An approach to the study of population dynamics of Aphanomyces euteiches in soil. Phytopathology 59:206-212.

14. Neter, J., Wasserman, W., and Kutner, M. H. 1990. Applied Linear Statistical Methods. 3rd ed. Irwin Publisher, Homewood, IL.

15. Pfender, W. F., Delwiche, P. A., Grau, C. R. and Hagedorn, D. J. 1984. A medium to enhance recovery of Aphanomyces from infected plant tissues. Plant Dis. 68:845-847.

16. Pfender, W. F., Rouse, D. I., and Hagedorn, D. J. 1981. A "most probable number" method for estimating inoculum density of Aphanomyces euteiches in naturally infested soil. Phytopathology 71:1169-1172.

17. Reiling, T. P., King, T. H., and Fields, R. W 1960. Soil indexing for pea root rot and the effect of root rot on yield. Phytopathology 50:287-290.

18. Sherwood, R. T., and Hagedorn, D. J. 1958. Determining the Common Root Rot Potential of Pea Fields. Wis. Agric. Exp. Stn. Bull. 531. Madison, WI.

19. Williams-Woodward, J. L., Pfleger, F. L., Fritz, V. A., and Allmaras, R. R. 1997. Green manures of oat, rape, and sweet corn for reducing common root rot in pea (Pisum sativum L.) caused by Aphanomyces euteiches. Plant Soil 188:43-48 